International Journal of Linguistics, Literature and Translation

ISSN: 2617-0299 (Online); ISSN: 2708-0099 (Print)

DOI: $10.32996 /$ ijllt

Journal Homepage: www.al-kindipublisher.com/index.php/ijltt

IJLLT

\title{
Utilizing Process Approach through IELTS Essay Practice in Teaching Writing for Medical Students through Online Teaching
}

\author{
Dina Gaber Zanaty \\ Lecturer of Linguistics, Faculty of Oral and Dental Medicine, Delta University for Science and Technology, International Coastal \\ Road, Gamasa City, Mansoura, Dakhliya, Egypt
}

$\square$ Corresponding Author: Dina Gaber Zanaty, E-mail: Dina.zanaty@deltauniv.edu.eg

\section{ARTICLE INFORMATION \\ Received: 15 September 2021 \\ Accepted: 02 October 2021 \\ Published: 30 October 2021 \\ DOI: $10.32996 /$ ijllt.2021.4.10.11}

\section{KEYWORDS}

Process Approach, IELTS, Essay Practice, Medical Students, Online Teaching.

\section{ABSTRACT}

Mastering the skill of writing means mastering a very powerful tool of expression. Hence, English language teaching is an integral part of training medical students in Egypt. Developing 'writing skills' is essential for their future career after graduation. Due to smartphones, autocorrect devices, and pre-prepared writing templates available online; students lack the competence in a very indispensable skill in their academic progress which is 'writing'. The main goal of this study is to investigate how 'writing' could be developed through the process approach in an academic semester during the period of quarantine in Egypt from 15 th of March, 2020 to $30^{\text {th }}$ of May, 2020, which coincidentally became an online teaching semester due to Covid-19 circumstances, an experiment involved (230) students in Oral and Dental Medicine Faculty at Delta University in their first year of study. There was a variety of research methods involved in this paper which included the theoretical and the practical ones in addition to inductive-deductive ones, observation, and analyzing techniques to reach data and statistical values of students. The results revealed a great improvement estimated by more than $60 \%$ in students writing performance after the application of this approach and demonstrating an ability to use proper terms and conjunctions in academic writing.

\section{Introduction}

Writing capability does not only include lexical varieties, sentence choices, punctuation usage, well-knowledge of cohesion and coherence, but also methods to organize and construct arguments at both micro and macro levels. There have been major paradigm shifts in teaching writing methods through the previous years. Many years ago, the process approach to teach writing had been very widespread. It altered the attention from focusing on the correctness of a piece of writing to the communicative macro-level of writing. The goal of the process approach in teaching writing is to give the students the space to determine how a piece of writing affects the reader. This paper investigated students' performance in writing before and after the usage of the 'process approach' as a teaching method for writing on many linguistic levels. Specifically, to ascertain if there were any tangible results in teaching writing to students using the process approach. There were some questions to find answers to, during the planning of this qualitative research project, and specific results to reach within a period of an academic semester. Despite time limitations, quarantine circumstances, virtual learning, and a confined academic period for me as a lecturer and for the students to hit the desired goals in a period of an academic semester.

There was a noticeable effect of this method. This sheds some light on how useful is the process approach as a means to communicative writing. The writing process is not an easy task; it daunts even native speakers or even those of higher education throughout their school years and in their academic ones. The process of discovering one's distinguished writing style, utilizing various forms and expressing thoughts and beliefs, being clear and organized is a complicated task for most academic students. The execution of this process is a must for academic students in Egypt. In addition to searching for a proper method to acquire academic writing, these students are overburdened more than native speakers with the technical and academic difficulties inherent in the teaching system.

Copyright: (C) 2021 the Author(s). This article is an open access article distributed under the terms and conditions of the Creative Commons Attribution (CC-BY) 4.0 license (https://creativecommons.org/licenses/by/4.0/). Published by Al-Kindi Centre for Research and Development, London, United Kingdom. 
The process approach to writing gives a solution to these problems and makes it easier for non-native English learners to discover their writing styles. This was the main investigation of this paper, to study the effect of implementing the process approach in writing within an academic semester for medical students.

Completion of a good piece of writing is a complex process for both native speakers and non-native speakers of English. If a native speaker writes in his language, there are rules and steps required to reach a good piece of writing. Therefore, revising and proofreading are a must rather than an option (Hinkel, 2002). Hence, writing is considered as a skill to be attained rather than an innate quality. Writing for dentists is as important as their medical courses. Egyptian Ministry of Higher Education constantly pursues achieving an educational goal that could not be fully fulfilled if one does not work to aspire to language development that allows a dentist to interact efficiently in the professional context.

Hence, English language teaching is included in the curricula of all specialties in medical faculties where developing language, extra-linguistic skills, communication skills are of priority.

In the medical sciences faculties, the objective of language teaching assumes achieving the students' communicative competence through the integration of the four skills: speaking, reading, listening, and writing. To achieve this, active methods must be introduced which expand and accentuate existing knowledge and skills as a necessity in the practice of the medical profession and the integral development of the health professionals and the medical researchers later on.

The knowledge medical students possess to write a good piece of writing with the complete writing elements is very limited. This problem is clarified by (Hinkel, 2002). He affirmed that most of the students do not have the required potentials needed for writing which obstruct their writing capability in delivering their writing successfully which is a crucial point for their success as doctors after graduation. It is the prober time that students in their earlier years of studying should put in their consideration the advantages they could reach from learning how to write as they are having too much trouble in this skill. This could assist them to produce skillfully written texts since writing is experienced in various academic areas. It is evident how English language instructors integrate writing skills in their pedagogy and instruction which is an essential indicator of the importance of writing. Thus writing plays an irreplaceable part in students' academic journey; it works for them as the channel to easily deliver thoughts and contemplations (Blanton, 1987).

Although it was mentioned above how the skill of writing is significant for instructors to involve in their pedagogy it is somehow neglected in the instruction process, as it only focuses on two sides, grammar and syntax, which hugely pinpoints how teaching the essence of writing could be obstructed. Recently, English language instructors began to pay attention to improve the methods of teaching and learning this particular skill.

Moreover, Rooke (2004) claimed that English language instructors deal with English writing instruction as a very complicated process and difficult mission especially for non-native speakers or learners who are specifically in medical fields who are not fully acquainted with a lot of expressions. Rooke (2004) asserted the importance of the role of English language instructors in teaching the skill of writing and its part in enhancing students' levels and boosting their performance in writing. Putting into consideration the significance of writing in the academic years of study, English language instructors should play their part in assisting students to be globally prepared and internationally acquainted with the latest trends in many fields that will benefit them later at work and with their linguistic skills. This is very clear in the IELTS (International English Language Testing System) writing parts, as it consists of two parts (describing a graph and writing an essay). It is emphasized that there is a dire need for multiple resources to enhance teaching and practicing this skill. Traditional methods of teaching writing have been proved to be outdated with students, leading them to use fixed templates and expressions that do not evolve with the frequently changing topics and trends. It is also assured that writing is just like other English language skills, reading, listening, and speaking; needs teachers to teach and instruct. He stressed that writing should be considered as a talent more than a skill.

Writing learners should pay attention to the four parts of writing (content, organization, grammar, and mechanism). Hence, researchers and scholars who are interested in education should give a top priority to discover new methods to reach the core of this skill as it only focuses on two sides, grammar and syntax, which hugely pinpoints how teaching the essence of writing could be obstructed. Recently, English language instructors began to pay attention to improving the methods of teaching and learning this particular skill by using an effective mechanism in teaching the writing process. There are various methods to teach writing known many years ago which helped many writing instructors. Out of these methods is the product approach which is already used widely by instructors, and the other is the process approach.

Yet, the discrepancy between both of them ignited non-stop arguments between researchers. Rooke (2004) clarified that the product approach stresses more upon building students' writing skills through "imitation" of language structures and molds. 
Furthermore, the process approach is very helpful in highlighting how students participated in the writing process, and how this process was communicated by the educators by learning the core and the significance of the ideas and the expressions used, and how they function inside a piece of writing.

Process approach has approved its efficiency in teaching writing to students and when it was used with the assistance of IELTS exam models for essay tasks, massive progress was noticed in students' performance in writing. IELTS exam has two parts in testing writing, one of them is concerned about testing the skills of writing an essay and how an idea is being delivered and conveyed through multiple stages; the first stage is to analyze the question and identify the task required, the second stage is to brainstorm and gather the ideas related to the topic, the third stage is to begin to organize the ideas gathered and write them into an introduction, body, and conclusion according to the type of the essay; whether it is argumentative, persuasive, etc. Finally, the fourth stage is checking the language and proofreading, and making sure that the essay is mistakes-free. The previous stage required in writing an essay in an IELTS exam is not much of a difference in the stages taught to students in process approach" which proved their success and efficiency like no other. This approach prepares students later to have the skill of technical and scientific writings as researchers and case history of patients especially students in the medical fields. It develops their ability to analyze, brainstorm, organize, and proofread their language on their own without resorting to technical autocorrect methods.

According to the CEFR (Common European Framework Reference of Languages), communicative competence is put into consideration by adopting different language activities that include: comprehension (reading), expressions, interaction and idioms, (speaking and listening), essay (writing). Added to them interpreting or translating. Each of these types of activities is applied through various contexts in English language teaching.

Accordingly, the acquisition of the English language and its skills requires special observation, so that each student can reach tangible results in the textual and written construction in the academic and social field, especially within distance learning. Although the programs of the English courses advocate the use of variable teaching techniques and procedures in the integration of the four skills, it is unquestionable that the teaching of written expression has been hindered by the predominance of the traditional methods of teaching. Thus, researchers who investigated this area affirm that the objective of English language teaching to medical students is not achieved at the desired levels, since they are graduated from medical fields with major deficiencies in writing that deter them from performing their duties as writing a case history for a patient, writing a medical report, completion of a description of a medical-dental case or even the simplest of all; taking notes in lectures or scientific conferences.

Other authors consider that in those societies where education has expanded, the impact of writing is profound. Writing preserves spoken language and culture. It also prescribes and enriches many language-oriented processes with extensive social implications. (Hedge, 2003).

The process approach in writing has not been only an object of interest but also a didactic strategy proposed for developing writing skills. It is an appropriate method for language improvement for graduates of the medical faculties and those who have shortcomings in their performances that do not correspond to expectations if the duration of the English teaching is taken into account (Nunan, D. 1996)

Despite the efforts made, the reduced possibilities of using the language in real life by students lead to the limited mastery of the medical terminologies related to their profession and the inability to use it productively in the texts required. Thus, it demands a lot of effort to transform this reality and meet the educational needs of students.

Corresponding to their linguistic needs and taking into account the results of observing students' levels, the analysis of the content taught in the English courses, and the assessment of written exams (quizzes, midterm, and final) which were held online as the existence of insufficient development of writing in English was evident. To solve this problem, it was proposed to develop the writing teaching approach in English for medical students at the faculty of Oral and Dental Medicine at Delta University.

\subsection{The objective of the Study}

This study was held to compare freshmen students' performance in Essay writing before and after the application of the process approach method represented in teaching IELTS essay writing during the period of distance learning which was inserted in their English language curriculum in their spring academic semester. Specifically, the study sought to investigate the following research questions:

1. What are the results of the performance levels of the writing of students in two stages; pre-test compared to post-test?

2. Did the process approach method for teaching writing through IELTS writing exercises during the distance learning period, contributed to improving students' performances in semantic, grammatical, and lexical aspects of writing? 


\section{Literature Review}

\subsection{Methods of Teaching Writing}

The methods of teaching writing have always been controversial yet ignored by teachers. It is essential to know that teaching writing did not have the expected and required attention to innovate creative ways to teach it. (Nunan, 1996) in (A Language Teaching Methodology) clarified that methods of teaching the writing skill have been neglected while other skills in the English language have not. (Tribble, 1996) explained the main reason behind neglecting teaching methods of writing is the "product approach" which mainly depends on reproducing writing mold. He added that this approach had been often condoned by language teachers for many reasons; one of them is, it is very convenient to apply, another reason it has been guaranteeing a stable performance of writing, and the last reason is, it has been frequently implemented among language teachers and instructors. Thus, it is effortlessly applied, practiced, and adopted by language teachers.

Although there are many strong pretexts to utilize the product approach in teaching writing, there are some shortcomings that should be pinpointed. According to (Tribble, 1996) the writing process mainly depends on three stages; pre-writing, preparing a draft, proofreading; typically, the product approach includes these stages with an essential concentration on the 'final result' of writing and not on the stages of writing that are included in the process approach which mainly exist in IELTS essay writing instruction. Usually, in the product approach, students are asked to apply these steps and stick to a specific writing template to produce a piece of writing. These steps of the product approach often decrease the teacher's participation in teaching the writing process and limit students' creativity. Thus, learning the skill of writing became unlikable to most of the students, especially those in the university who will need these skills in their medical career later. It became more of an obligation than a field of expression and creativity, that is why the process approach started to emerge.

\subsection{The Process Approach}

Raimes (1985), stated that the process approach came up with another perspective different from the product approach. The process approach mainly focuses on the level of creativity in a writer. It highlights the improvement of teaching writing methods more than following non-innovative and fixed writing molds. Thus, the process approach helps students in every stage of the writing process. To clarify, the process approach is not similar to any of the conventional approaches that give a fixed writing template that discourages creativity. On the contrary, the teaching and guidance occur throughout the whole writing process in every stage, not only before and after like other conventional methods. The process approach includes many stages of checking and proofreading unlike other approaches, this ensures that it is not characterized by being systematic and regular. It focuses on revision and going backward and forward in a piece of writing to spot any shortcomings and correct them. It mainly focuses on students' creativity.

\section{Methodology}

A quantitative investigation was conducted with 230 students in the first year of their dental study to develop their writing skills while studying English for specific purposes as an academic course at the faculty of Oral and Dental Medicine, during the period of quarantine in Egypt from 15 th of March, 2020 to 30 ${ }^{\text {th }}$ of May, 2020.

\subsection{Participants of the Study}

This study was conducted at Delta University for Science and Technology, a private university in Egypt, at the faculty of Oral and Dental Medicine on freshmen students. These students had an English language placement test before enrolling in the academic year and in the English language course, so they have a minimum writing ability as the placement test does not accurately measure their writing skills because it depends mainly on multiple-choice questions. Students who participated in this test have been chosen randomly so that the experience would give more accurate results without depending on the levels of English language proficiency and their grades.

The pre-experimental design chosen was the pre-test and post-test variant with a group of 230 students. For this goal, many of the tasks were designed and applied that was structured in four stages:

\section{1- Diagnosis:}

This stage is aimed at diagnosing difficulties in the writing practice. For this, an online test was applied.

\section{2- Planning:}

It is the design of the tasks essential for the achievement of the proposed objective, as well as its timing within the course program in compliance with the content and with the purposes of their future career.

\section{3- Execution:}

At this stage, the different tasks are introduced and explained to the students through the website of the university and Facebook group. 


\section{4- Evaluation}

It is carried out throughout the process of implementing the tasks and activities and ends up with the application of a final evaluation (test).

As methods of the theoretical level, the analytical-synthetic, the inductive-deductive, the historical-logical, as well as the systemic approach were used; at the empirical level, document review and analysis observation were used. As techniques for obtaining more accurate results, tasks were selected, in addition to statistical procedures were performed to verify the status of the writing potentials and evaluate the effectiveness of the process approach method in writing after its application.

\section{Results}

For the analysis of the state of the writing skill before and after applying the process approach in writing, the following dimensions and indicators were set and observed:

\subsection{Dimension I: Semantic Indicators}

\section{Table 1: Change of the semantic aspect before and after the application of the Process Approach}

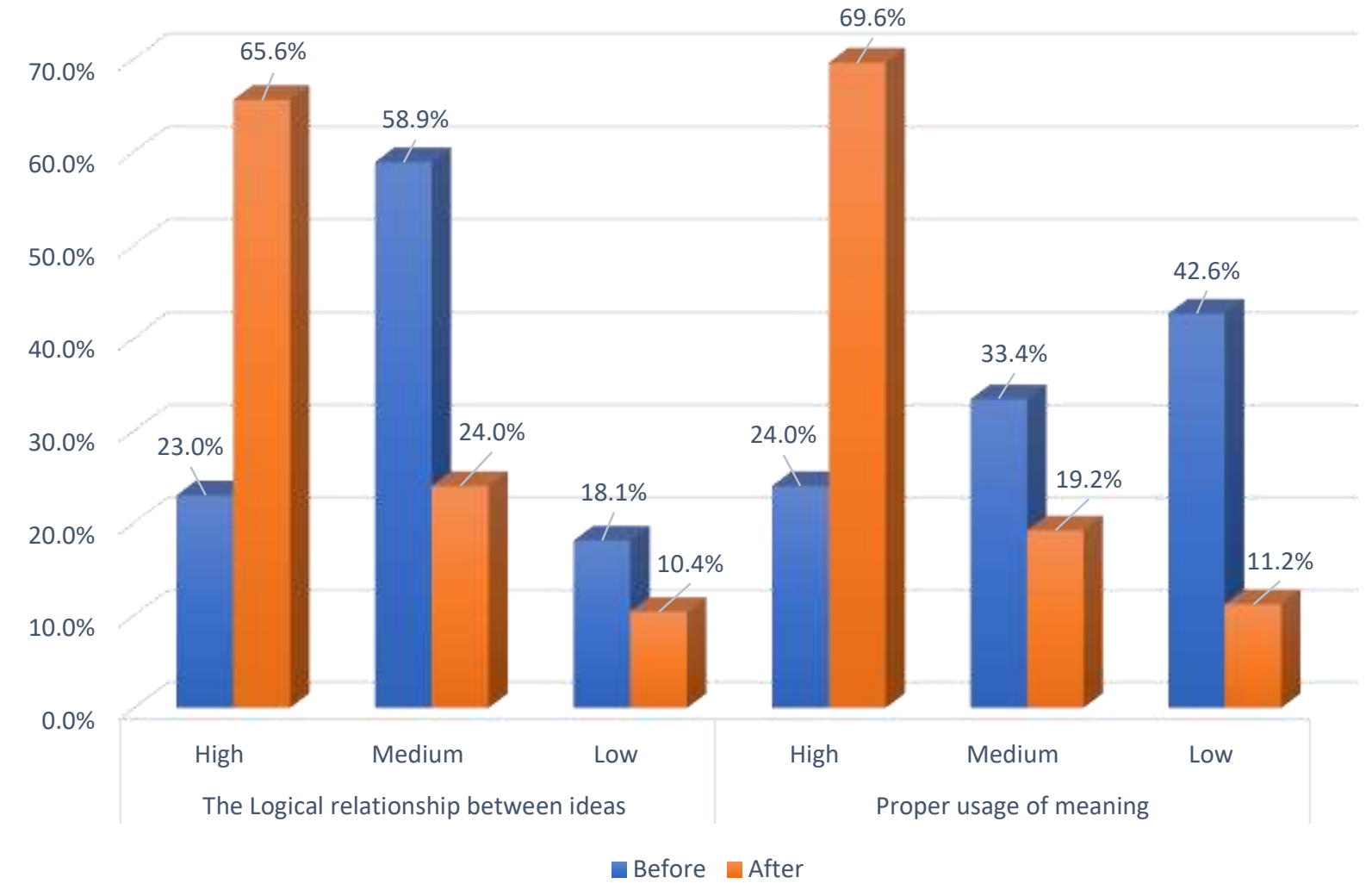

It entails:

- $\quad$ The logical relationship between ideas.

- $\quad$ Adequate usage of the meaning of words.

It also includes knowledge of coherence as it is an essential characteristic of students' ability to write a coherent piece of writing. (Couzjin, \& Rilaarsdam, 2005). 


\subsection{Dimension II: Grammar Indicators}

Table 2: Change of the grammatical structure aspect before and after the application of the Proçess Approach

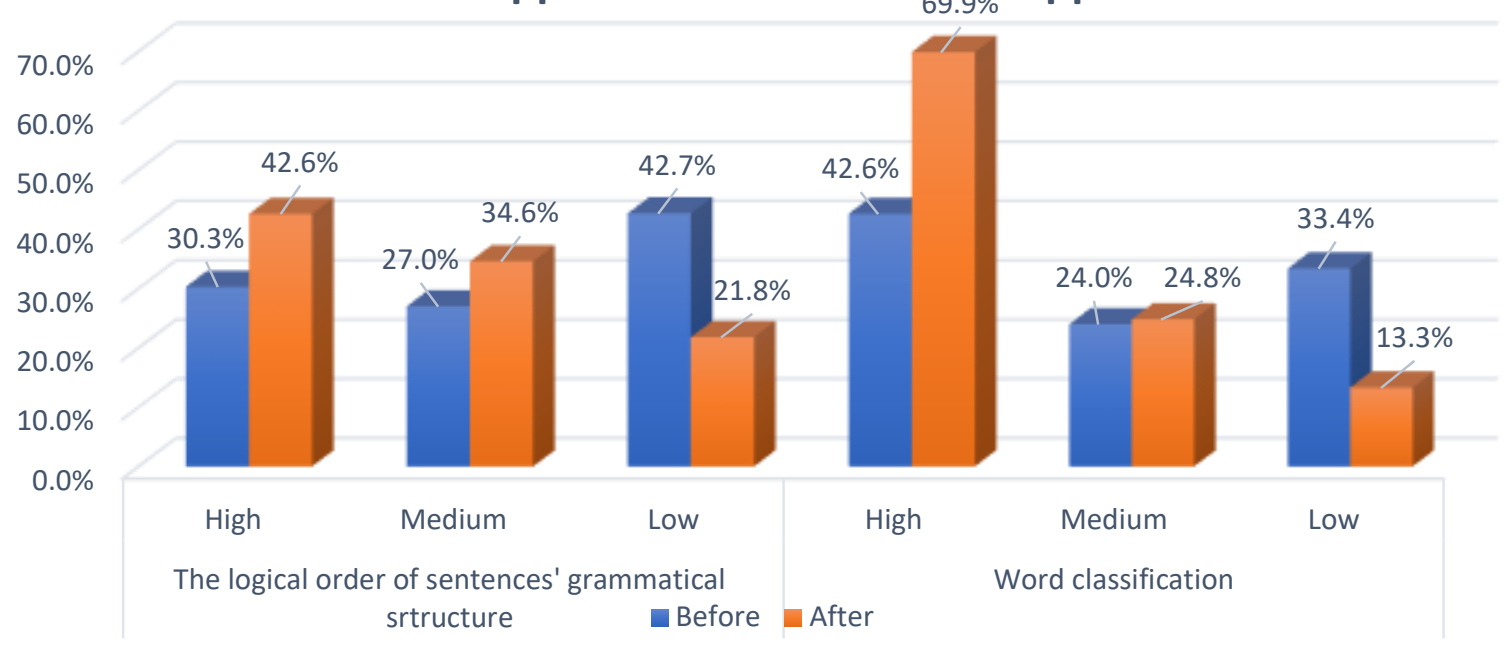

It entails:

- Logical order and relation of words taking into account the correct use of grammar which includes many factors as sentence structure, subject-verb agreement, the proper classification of words, the ability to use the passive voice to convey objectivity in their writing.

\subsection{Dimension III: Lexical Indicators}

\section{Table 3: Change of the lexical aspect before and after the application of the Process Approach}

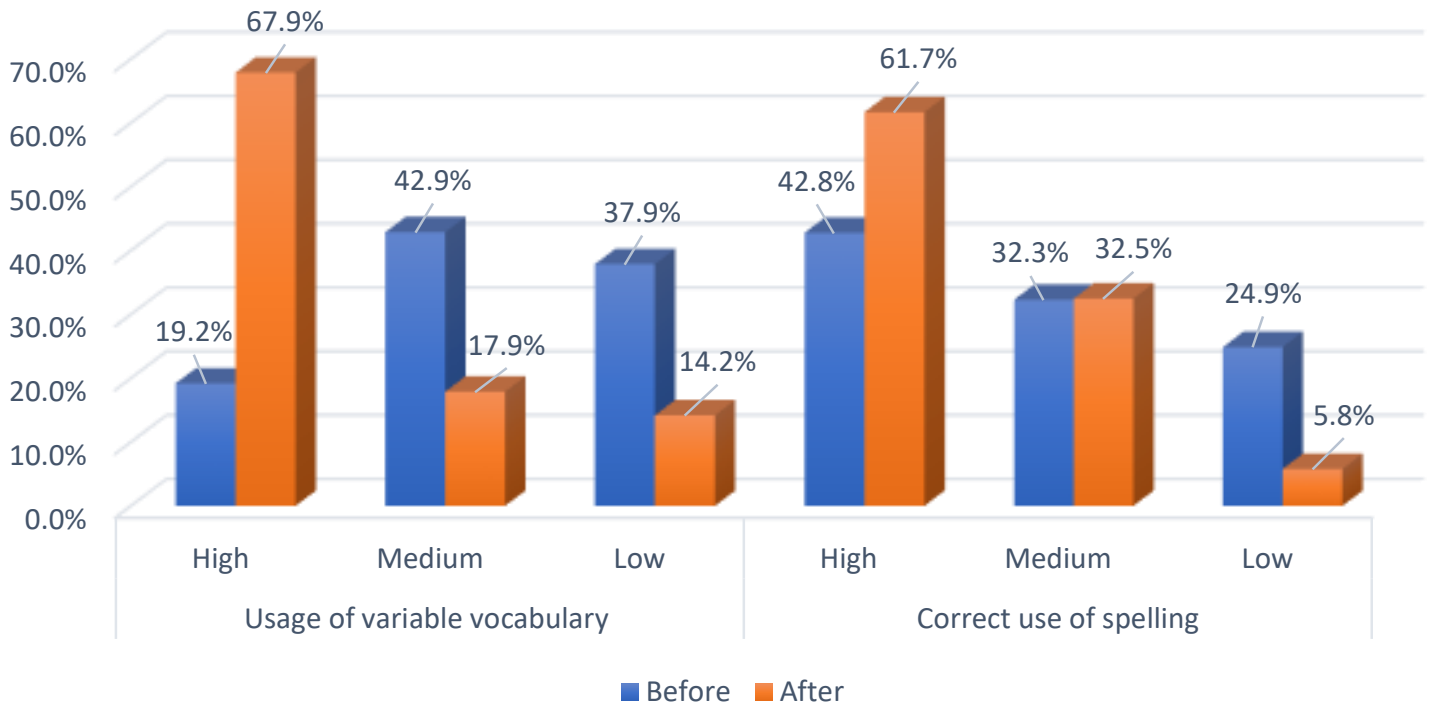

It entails:

- Use of vocabulary with specific purposes appropriate to the context.

- Correct use of spelling rules in general.

- $\quad$ The ability to use vocabulary variably to produce a sophisticated piece of writing. (Ferris, 2014). 


\section{Discussion of Findings}

Table (1) shows the levels in which students were located taking into account the semantic dimensions, the most affected indicator was the appropriate use of meaning with $42.6 \%$ at the low level. This indicator rose to higher levels after the application of the process approach.

The second aspect was the grammatical dimension. Table (2) shows the levels reached by the students in the aspect of the structure and element of writing. $42.7 \%$ of the students were in the lower levels in the initial stage results that decreased to only $21.8 \%$ in the post-application stage of the process approach.

The lexical dimension is reflected in table (3); only $19.2 \%$ of the sample tested was at the higher level in terms of the variable vocabulary usage, with an increase of $67.9 \%$ after the application of the process approach method. There is also progress observed related to the spelling due to the last stage of the process approach method which is checking and proofreading.

The formation and the ability of writing is a complex process, which results in products or (texts) that are the result of a dynamic process where the lingual components directly affect and motivate the three dimensions selected to diagnose the samples elicited from students.

An essential element in developing the writing skill is the (exactness) or the (accuracy) of the meaning of the words to be used to achieve communication in its context by the demonstration of "the proper use of meaning" of the words inside a context which could increase their comprehension of the professional meanings from $24 \%$ to $69.6 \%$.

Students while writing the essay vary between the novice and the experienced throughout the different stages of writing;

a- Analyzing the question and identifying the task.

b- Brainstorming and mind-mapping.

c- Organizing.

d- Checking and proofreading.

In the mind-mapping stage, novice students tend to ask themselves: How much do they know about a topic, whether they have enough information to insert into their composition. On the other hand, experienced students are more concerned with the rhetorical situation (i.e., objective, audience, and context) in their essays.

Usually, many writing instructors explain the writing process as a linear process (Badger, R. \& White, G. 2000). (Hyland, K. 2003) connected four distinguished steps in writing. First, in the "identification stage", a writer identifies the task required whether it is a persuasive or argumentative essay. Stage two is "brainstorming and mind-mapping" the ideas are to be phrased later through step three which is "writing and organizing". Typically, an essay should have an introduction, body paragraphs, and a conclusion. The fourth step is checking and proofreading, some writers execute this step-through re-reading their essay to be certain they have fulfilled and sufficed the essay's task. Among the most frequent errors detected after the proofreading stage on a grammatical dimension; are mistakes of subject/ verb agreement in being singular or plural, and the confusion in the usage of tenses or when they should use present or past tenses, the lack of using the appropriate grammatical patterns as in "it hasn't $t$ " instead of "it doesn't have". On a lexical dimension, the misusage of verbs as "teach" and "learn" by mingling their connotations in the sentences is frequent, the absence of using variant conjunctions between the sentences and the paragraphs to deliver a purpose of contradiction or conviction, adding the letter "e" at the end of the words, using informal language in writing as "good stuff", "dude", "buddy" and other colloquial expressions students used to hear in movies, the misuse of the singular and plural words in their correct context as "tooth" and "teeth", also the mix between the usage of "advice" and "advise". Finally, semantically they have some miss-conceptualization about some meanings as they misplace them, a thing which can completely change the meaning, as the use of "fabric" to refer to "oral tissue", "black" instead of "plaque", etc.

Crossing the proofreading stage allowed students to associate and acquire new knowledge about these mistakes, their corrections and to incorporate them in their writing frequently. The proofreading stage enabled students to get a better interpretation of the meaning of the words using the correct syntax and greater coherence and cohesion between the form and the content. This is demonstrated by the rise of the upper levels in both indicators with $62.7 \%$ and $69.6 \%$ respectively of students tested.

The insufficiencies in the grammatical dimension for example, where only $30.3 \%$ of the students reached the highest level of little mastery of the use of the elements such as prepositions, adverbs, phrases, and expressions of transition, which are considered important to achieve unity of thought and continuity in the written text are due to a lack of the inclusion of these elements as vital parts of the language, not only as rubrics and equations as they were taught in high school. Another reason behind this is that they show a lack of linguistic practice. This situation was reversed after focusing on the process approach method as $42.6 \%$ of the students were at the high level by writing a harmonic text based on the selection of information, planning, structure, and development of ideas. 
Reflection, memory, and creativity were coherently related to the use of appropriate language although the ability to combine ideas in another language is a complex and difficult process that became applicable after the usage of the process approach.

Ignorance of the category in which the words are grouped according to the place and the functions they occupy in the sentence as nouns, verbs, adjectives, pronouns, etc., negatively affected $58.9 \%$ of the sample located in the medium levels. The limited mastery of the word-formation widely used in the terminologies of dentistry also stood out among the shortcomings. By reflecting on these results, it is agreed that grammar should be transmitted to students in a practical way, where the importance of knowledge and classification of words in the contextual construction of the sentences and written texts are applied.

Thus, the process approach in writing accompanied with a professional purpose or teaching English for specific purposes is often more motivating and effective as they are closely linked to the characteristics of the vocabulary that treats and prioritizes the needs of the English learner to cope with study programs.

According to (Heiman, T., 2003) when referring to the process approach in teaching writing, all decisions regarding content and methods must be based on the students' reasons for learning. The process approach encourages the interrelation of language knowledge. This means that English class for specific purposes including teaching them essay writing gives the students a reason to learn context to use and a linguistic atmosphere to practice. It also focuses on the use of the technical language of a particular professional field.

Despite the above, the results obtained reveal the poor command of the students of the terminologies proper to their specialty, since only $19.2 \%$ of the sample reached a high level. These findings could be linked to the fact that dental/medical terminologies are taught only in the third year of their dental study, which limits the learning time in this regard.

It is pivotal to put this aspect into consideration as (Oshima, A. \& Hogue A. 2007) pointed out that a member of a scientific community cannot carry out his research activity without being aware of the steps of the process approach in writing and applying them.

\section{Conclusion}

The process approach in writing has proved itself to be very effective in dealing with writing common problems for EFL students. That was clear when the results of students' performance in writing were compared before and after the application of the process approach in writing. The most significant advantage of the process approach in writing is that it is very specific in treating writing difficulties. Of course, it is the most efficient in developing writing skills for students, but newer methods are needed. However, the process approach has shown proficiency through the results of students especially in improving the content, a variance of vocabulary used, and organization of a piece of writing. It is very beneficial in creating a reciprocal learning relationship that does not depend only on the teacher but mainly depends on the students' capabilities.

Using the process approach in writing in professional activities activated interest and motivation by recognizing its usefulness in professional practice from a medical perspective in required case reports, researches, essays, and filling of medical and clinical records, which elevated the performance of writing reached by students.

Thus, written communication is very broad, develops thinking, and influences students' language. That is why it is considered a fundamental instrument necessary to prepare students to avoid spelling mistakes and correctly use punctuation marks.

However, during the diagnostic stage, the results revealed inadequacies, with $30.0 \%$ of those sampled at the lowest levels. This coincides with similar results obtained by other dental specialized professors who consider that learning linguistic rules is not necessarily important in classes, and this aspect is left to the independent work of students.

Process Approach when applied; greatly strengthened all three dimensions and the performance of the students improved compared to the initial state.

The didactic material designed and applied, which includes: essay writing rules, academic writing fundamentals, and dental health terminologies, have a close connection to each other and forms a unit that contributes to the achievement of the objectives set. They provide a series of activities that allow the development and the improvement of logical understanding and reasoning in the construction of written texts, linking the rhetorical and practical, the instructional with the educational. It reached a required impact on the teaching of the writing process and on the development of writing ability.

\section{Summary}

Most of the writing obstacles students faced during learning how to write an essay were minimized by the application of the process approach. The structure problems, misspelling and, lack of organization were problems handled by proofreading and revising methods acquired by the process approach method. It is known that the English language does have specific molds that 
should be stuck to. That is why the process approach in writing and the multiple opportunities of editing and resurrecting a piece of writing were ideal for many cases of students to improve their performance in writing other than sticking to a specific mold.

\subsection{Recommendations}

Further research on a larger number of students from different scientific fields (not only the medical field) to pinpoint the effect of the process writing approach in improving the quality of writing.

\section{References}

[1] Blanton, L. (1987). Reshaping ESL students' perceptions of writing. ELT Journal Volume 41/2, p. 112-118. Oxford University Press

[2] Couzjin, M. \& Rilaarsdam, G. (2005). Learning to Read and Write Argumentative Text by Observation of Peer Learners. Effective Learning and Teaching of Writing: A Handbook of Writing in Education. Second Edition. Kluwer Academic Publishers.

[3] Hedge, T. (2003). Writing. New York, Oxford University Press.

[4] Hinkel, E. (2002). Second language writers' text: Linguistic and rhetoric features. Mahwah, N.J. Lawrence Erlbaum Associates.

[5] Nunan, D. (1996). A Language Teaching Methodology. London, Longman.

[6] Raimes, A. (1983). Technique in Teaching Writing. New York: Oxford University Press.

[7] Raimes, A. (1985). What unskilled ESL students do as they Write: A Classroom Study of Composing, TESOL Quarterly 19 (2): $229-258$.

[8] Redman, P. (2006). Good Essay Writing: A Social Sciences Guide. New Delhi, Sage.

[9] Rooke, C. (2004). The Clear Path: A Guide to Writing English Essays. Thompson Nelson, Toronto Ontario.

[10] Tribble, C, (1996). Writing, New York, Oxford University Press 